\title{
An Examination of the Nutritional Care and Feeding Behavior of an Adult Female Lion (Panthera leo) in Mvog-Betsi Zoo in Yaounde, Centre Region, Cameroon
}

\author{
Melle Ekane Maurice $^{1 *}$, Manjo Chiara Keafon ${ }^{1}$, Kato Samuel Namuene ${ }^{1}$, Ewane Divine ${ }^{1}$, Mbole \\ Veronique $^{1}$ \\ ${ }^{I}$ Department of Forestry and Wildlife Management, Faculty of Agriculture and Veterinary Medicine, University \\ of Buea, P. O. Box 63, Buea, Cameroon
}

*Corresponding Author: Melle Ekane Maurice, Department of Environmental Science, University of Buea, P.O. Box 63, Buea, Southwest Region, Cameroon

\begin{abstract}
Lions are iconic species of wildlife, both loved and feared. While they do not have the striking color patterns of a jaguar or the cultural significance of a tiger, the striking mane and complex social structure make them unique among all the wild cats. The objective of this research was to examine the nutritional care and feeding behavior of the lion in Mvog-Betsi Zoo. Data collection was done for a period of 3 months, 6 days each week, from 7:00am-6:00pm. Hygiene of both the feeding and non-feeding environment (animal enclosure), food-type, feeding behavior, and feeding position were recorded in the data sheet. The results of the study showed a significant link between feeding behavior, hygiene of enclosure, food-type, feeding position, and feeding time, $r=0.350 P<0.05, r=0.276 P<0.05, X 2=5.962 d f=2, P<0.05$, and $r=0.302, P<0.05$ respectively. The animal enclosure was $70 \%$ dirtier than clean, though the animal still fed in this enclosure, it was remarked with an unprecedented aggressive behavior. Also, beef and chicken were more accessible in the meat market, $60 \%$ and $40 \%$ respectively, facilitating the management of animal feeding. Interestingly, the behavior of lying while in captive feeding was dominant over standing, $87 \%$ and $13 \%$ respectively. Aggressive behavior was the most observed feeding behavior and recorded $60 \%$, while walking was the least, $13 \%$. Additionally, a significant association was recorded between the hygiene conditions of non-feeding environment on the animal position and behavior, $X 2=18.592 d f=2, P=0.000$ and $X 2=4.617 d f=6, P<0.05$ respectively. Furthermore, the animal displayed a spectrum of behaviors during the non-feeding periods, and the behaviors were resting, moving, roaring, and auto-grooming, recording an observation of 66\%, 15\%, 10\%, and $9 \%$ respectively. The adult female lion of Mvog-Betsi Zoo is principally fed with only cattle meat and chicken, however, feeding this animal with a whole animal carcass like a sheet, goat, etc. is very important at least once monthly to simulate a healthy wild feeding.
\end{abstract}

\section{INTRODUCTION}

Lions are endemic in African and Asian forest where they are successful predators except where in conflict with agriculture and human pressure. They persists mainly in open woodland, brush, scrub and grassland habitats, with additional populations found in arid, forested or mountainous regions. Lion prides defend home ranges which are size-dependent on prey and water availability and range from approximately $50 \mathrm{~km}^{2}\left(19 \mathrm{miles}^{2}\right)$ to over $700 \mathrm{~km}^{2}\left(270 \mathrm{miles}^{2}\right)$ (although with the majority of activity occurring in a central area) (Haas et al., 2005). Lions are opportunistic predators, and acquire approximately $40 \%$ of their intake from scavenging (Haas, et al., 2005). Lions may hunt individually or as a group, with greater success in tandem. In the Kalahari, lions were successful at 40-50\% of hunts, depending on prey (Eloff, 1984). Stalking time was also dependent on prey, for example 7 (small unpreferred prey) to 30 minutes (large preferred prey) (Hayward \& Kerley, 2005). Twelve to 50 kills per year are estimated per lion, depending on prey availability (Eloff, 1984).

Lions spend the majority of time (20-21 hours/day) inactive, approximately 2hours walking and 1 hour eating, although activities may vary significantly between days. Peak activity (80-100\%) occurs at night (Clarke \& Berry, 1992; Visser, 2009). Lions will hunt and consume a variety of prey but the majority of kills range between 40-250 kg with an average weight of $115 \mathrm{~kg} / \mathrm{kill}$. If a larger prey is available, lions will select for prey weighing 190-550 kg (Hayward \& Kerley, 2005). Referred species include wildebeest 
(Connochaetes taurinus), gemsbok (Oryx gazella), buffalo (Syncerus caffer), giraffe (Giraffa camelopardalis), porcupine (Hystrix africanus tralis) and zebra (Equus buchelli) (Hayward \& Kerley, 2005). Similar prey preferences were found in Shamwari, where the average mass of prey killed was $132 \mathrm{~kg}$ (Rapson \& Bernard, 2007). Lions persisting in arid regions are restricted to smaller prey (average $55 \mathrm{~kg}$; median $25 \mathrm{~kg}$ ) but small prey is associated with higher cub mortality due to starvation (Eloff, 1984).

Animals in zoos inhabit a much less complex environment than their counterparts in the wild. This can limit their ability to control the external stimulation to which they are exposed (Carlstead, 1996). Possessing an element of control is essential for animals to be able to adapt to their environment and to support their wellbeing (Sambrook \& Buchanan-Smith, 1997). Therefore, one of the more important goals of an enrichment program should be to offer the animals a complex exhibit that gives them choices and a way to control their environment, which, in turn, can enhance welfare. This program should target speciesappropriate behaviors that are in the animals' best interest and allow the public to observe their natural behaviors.

When large prey is captured, lions may spend several hours consuming the kill (Visser, 2009). Kalahari lions were reported to leave on average 1/3 of the carcass (Eloff, 1984), while lions in managed settings consumed $90 \%$ of hind limbs offered and 100\% of skin (Smith et al., 2006). In 4 hours of video tape on 5 kills by Masai Mara lions, only about $12 \%$ of feeding observation included bone and then only when muscle was present (van Valkenburgh, 1996). In addition to vertebrate carcass, traces of soil and grass were common in lion stomachs (Smuts, 1979). Lions may go several days between kills either consuming and digesting large carcasses or seeking prey (Eloff, 1984). In Namibia, lions were observed to eat every 2.5 days on average (Clarke \& Berry, 1992), another population was reported to average one kill every 4 days (range 1-13 days) (Smuts, 1979) and a group of Kalahari lions was reported to go as long as 8 days without a kill (Eloff, 1984). Others report lions eating every 1.5 to 3.5 days, depending on prey availability (Altman et al., 2005). Of 257 stomachs of free-ranging lions, $47.1 \%$ were found empty (Smuts, 1979).

Lions in zoos can be maintained on diets consisting of commercially available meat mixes, whole prey, bones, carcasses, and muscle meat diets balanced with supplements. Some or all of these ingredients fed in combination should meet the target nutrient ranges for domestic cats. Commercially prepared meat mixes should be formulated to meet the nutrient needs specific to cats. As such, these products have the advantage of requiring no additional supplementation. However, soft diets provide little abrasion for good dental health and thus should be fed with whole prey, bones or carcass. Meat mixes have traditionally consisted of predominately horse or beef. More recently, pork products have become available (Watts, 2011). In general, these diets are well digested by lions. Studies comparing digestibility of horse and beef diets fed to large cats (lion, cheetah, tiger, jaguar) and domestic cats show high digestibility of dry matter (75-90\%), organic matter (79-96\%), crude protein $(81-97 \%)$, and fat $(92-97 \%)$ with variability attributable to level and type of fiber, collagen content, ingredients and possibly species (Vester, et al., 2010; Wynne, 1989). Domestic cats fed the same diets had similar or greater nutrient digestibilities further supporting the cat as an appropriate model for exotic carnivores. Commercial meat mixes contain little fiber (3\% max, dry matter basis) with sources typically either cellulose or beet pulp. Cellulose is considered unfermentable and beet pulp moderately fermentable. Fermentable fiber has been suggested to promote intestinal health in domestic cats by supporting intestinal cells and micro- flora (Barry, et al., 2010). Small exotic felids (leopard cat, caracal) have been maintained on diets including fructooligosaccharides, another fermentable carbohydrate (Edwards et al., 2001).

Studies on wildlife feeding in zoos are common in developed nations but not in Cameroon. The high cost of feeding associated with wildlife such as lions has been a deterrent to their management in zoos in the developing countries. Feeding a zoo lion with a whole animal carcass like goat or sheep on a regular basis is costly to the zoo management, alternatively frozen beef and chicken are the immediate options. Though, the provision of frozen beef and chicken can still sustain the animal's feeding health, the option of feeding enrichment consideration for proper management of the animal's diet must be respected in captivity.

\section{MATERials AND Methods}

\subsection{Description of the Study Area}

Mvog-Betsi Zoo- Botanical Garden is both a zoological and botanical garden, located in Yaounde VI District, has an of area of 4.70 hectares, and it's situated between latitude $3^{\circ} 7^{\prime}$ and $3^{\circ} 9^{\prime} \mathrm{N}$ and longitude 
An Examination of the Nutritional Care and Feeding Behavior of an Adult Female Lion (Panthera leo) in Mvog-Betsi Zoo in Yaounde, Centre Region, Cameroon

$11^{\circ} 4^{\prime}$ and $11^{\circ} 6^{\prime} \mathrm{E}$ (Edmonds, 2015). The zoo has a boundary with Nkolbisson, Melen, Mini-Ferme, and Etoug-Ebe neighborhoods in the north, south, east, and west respectively. This zoo was created in 1951 by a German called Pfeiffer and later handed over to Cameroon government. Presently, the zoo is managed by Ministry of Forestry and Wildlife, and it homes 29 species of wildlife and 36 species of flora (Edmonds, 2015).

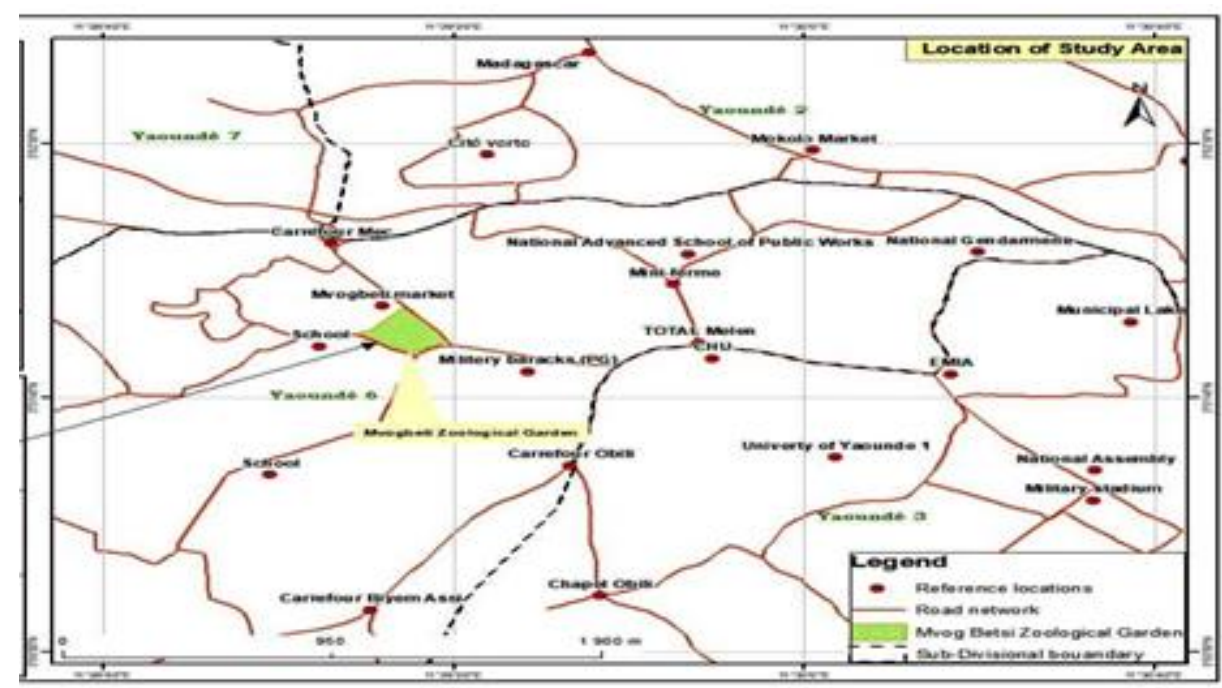

Fig1. Map of Yaounde showing Mvog-betsi Zoo-Botanical Garden

\subsection{Data Collection}

Data collection of this study was done for a period of 3 months, 6 days each week, from 7:00am-6:00pm. The adult female lion was observed for three to six hours each day and this was done from July to August. Data was collected on both feeding and non-feeding days at different time intervals, and recorded on check-sheets. During this period, the animal behavior was observed before feeding, during feeding and after feeding. On non-feeding days, observations were done at various time intervals on the behavior of the animal when resting, auto-grooming, walking and roaring. The focal data collection was done within an interval of 10 minutes, during this period observations were recorded on feeding, moving, resting, grooming, aggression and roaring. Hygiene of both the feeding and non-feeding environment (animal enclosure), food-type, feeding behavior, and feeding position were also recorded in the data sheet. Behavioral data can be collected in several ways (Altmann, 1974). In categorizing these methods, Martin and Bateson (2007) distinguish between sampling rule (whose behavior is watched and when) and recording rules (how the behavior is recorded).

\subsection{Data Analysis}

The frequency data generated were analyzed by the use of statistical tools. Perason chi-square $\left(\mathrm{X}^{2}\right)$ and correlation were used to compare some variables (Melle et al. 2017). The feeding behavior, hygiene of lion enclosure, food type, feeding position, and non-feeing behaviors were analyzed by using both the inferential and exploratory statistical models.

\section{RESULTS}

The study carried out on the nutritional care and feeding behavior of a captive lion (Panthera leo) in Mvog-Betsi Zoo in Yaounde recorded a significance on hygiene of the enclosure, food-type, feeding position, and feeding time against feeding behavior, $r=0.350 \mathrm{P}<0.05$ (fig.2), $\mathrm{r}=0.276 \mathrm{P}<0.05$ (fig.4), $\mathrm{X}^{2}=5.962 \mathrm{df}=2, \mathrm{P}<0.05$ (fig.6), and $\mathrm{r}=0.302, \mathrm{P}<0.05$ (fig.8) respectively. Lions are big cats endemic in the savanna ecosystem of Africa, and are very furious hunters in the wild. Felids are known to be among the most attractive wildlife in protected area in this continent, however, their population decline over decades has resulted to the captivity option of managing them in some countries. Nevertheless, cats are generally clean and in the wild feeding on their prey is done most in a comfortable environment, the reason they avoid feeding on decaying and stinking meat. Neglecting proper hygiene rules in a captive lion enclosure is not good for the health of the lion and its feeding. The zoo management authorities in Mvog-Betsi are very much aware of the health consequences of these animals, especially 
on zoonotic diseases that the animals could be transmitted in a poorly maintained animal enclosure in the zoo. Moreover, zoo visitors coming to watch the lion and other wildlife would receive offensive odor from these enclosures, which may not speak good of the management. Cats are clean animals, thus, a cleaner environment or enclosure would enhance their management in captivity. The animal enclosure was $70 \%$ dirtier than clean (fig.3), though the animal still fed in this enclosure, it was remarked with an unprecedented aggressive behavior.

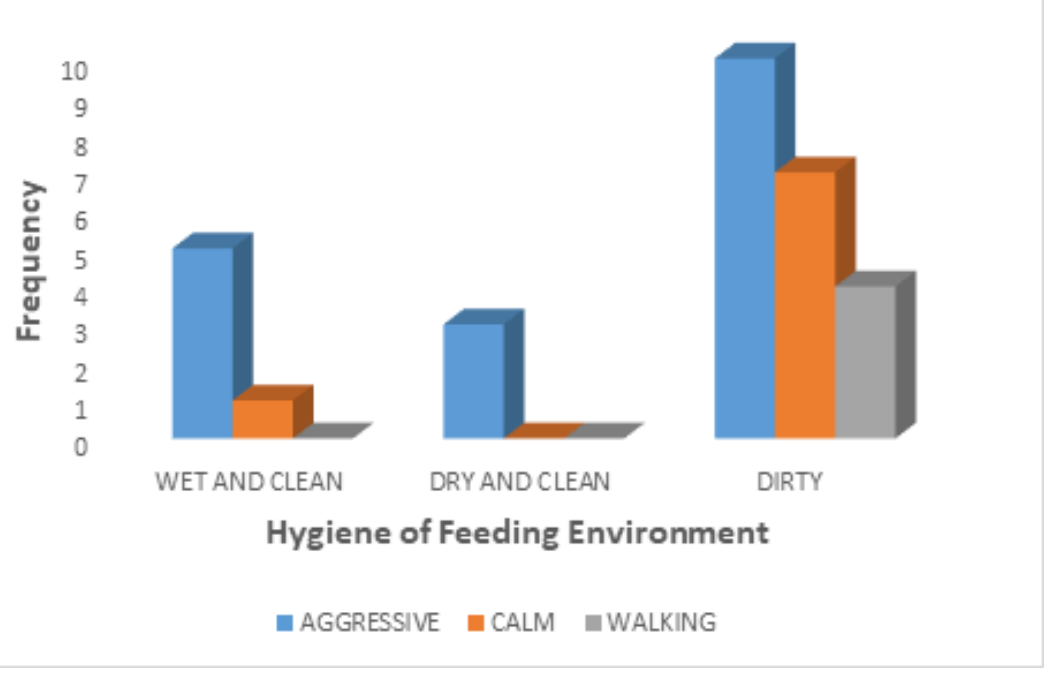

Fig2. Feeding behavior and hygiene of enclosure

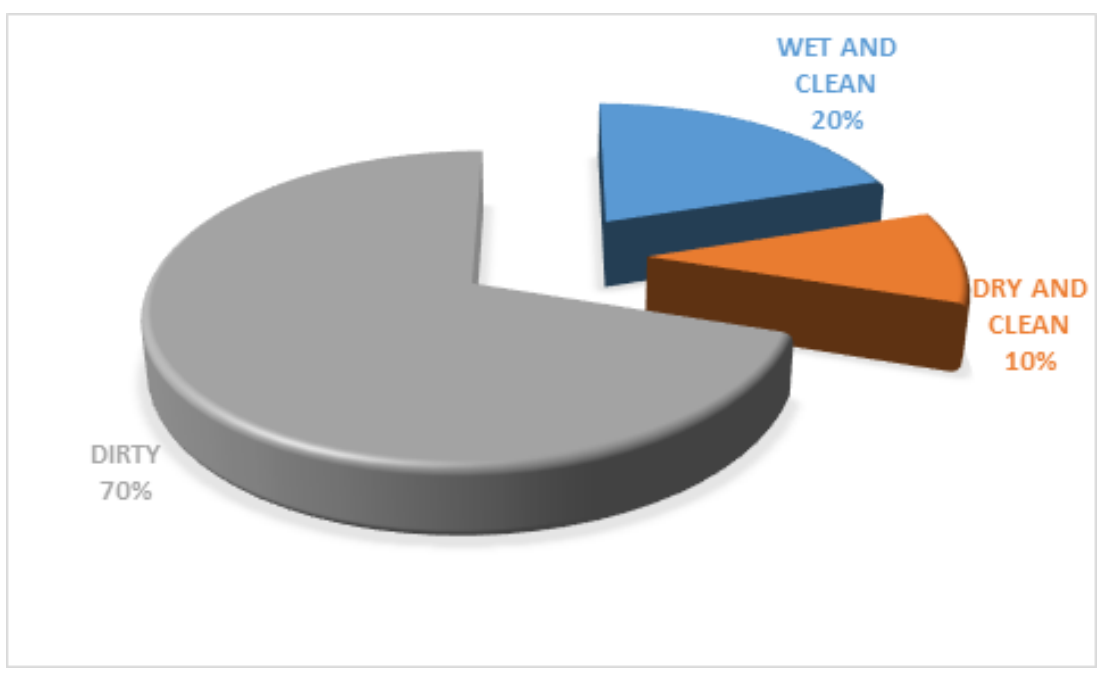

Fig3. Hygiene condition of the enclosure

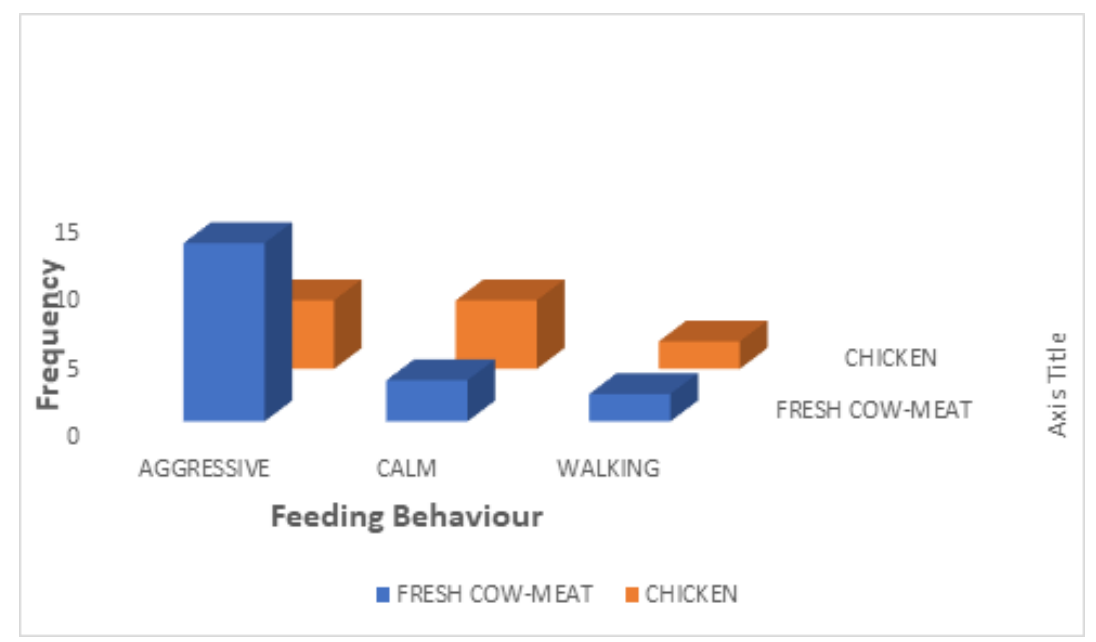

Fig4. Food-type and feeding behavior 
Lions are selective feeders in the wild environment but this might not be the case in captivity since there is a heavy financial cost attached to their feeding. The Mvog-Betsi Zoo management in Yaounde is financially over stretched, hence the lion is fed only $10 \mathrm{~kg}$ of frozen beef or chicken once a day. Strangely, the female lion is well adapted to this feeding method and was observed physically healthy. Providing a life animal to feed the female lion was never given a possibility due to financial implication. More so, beef and chicken were more accessible and available in the meat market, $60 \%$ and $40 \%$ respectively (fig.5), facilitating management.

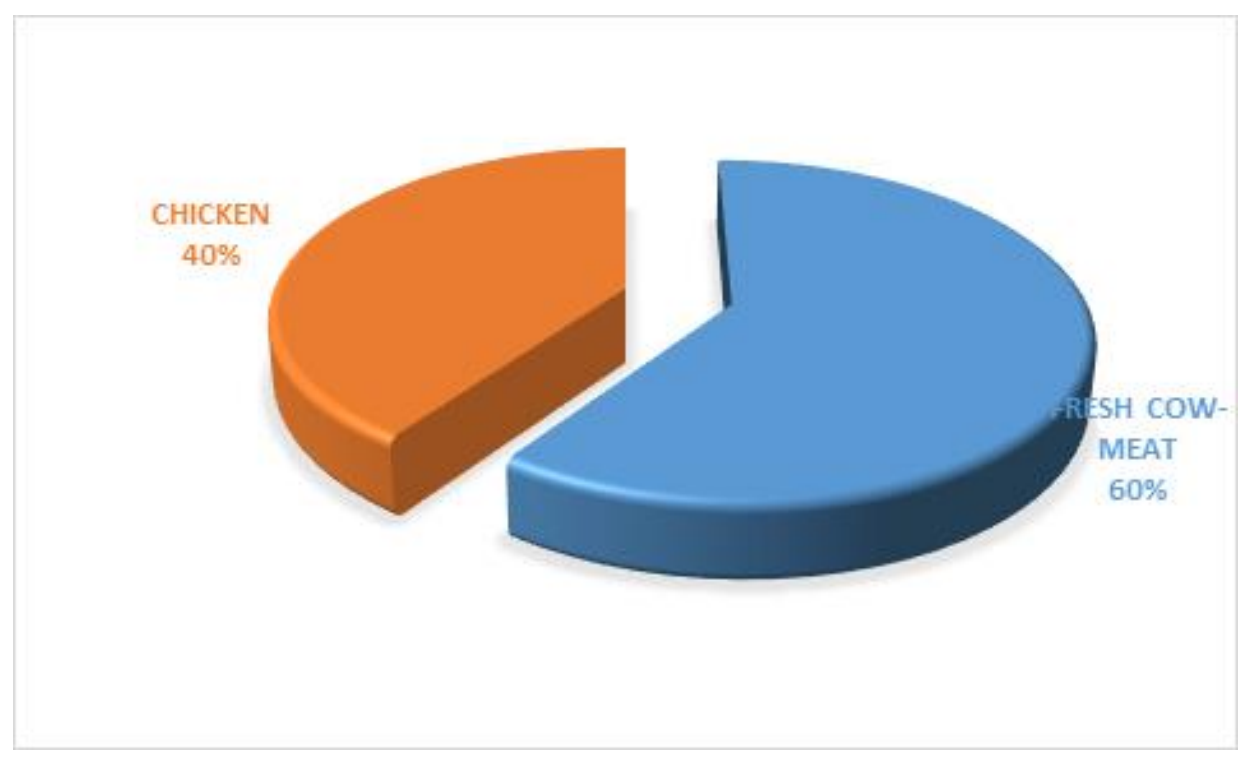

Fig5. Food-type

Cats are known to rest and feed most while lying either in the wild or in captivity. This study has confirmed this on the animal feeding behavior. Wild animals display a spectrum of several physical positions during feeding, such as standing, lying, and moving. The captive environment is small for a big cat like the adult female lion with a large home and feeding range in the wild, though some wild behaviors are witnessed sometimes on these animals while in captivity much is still hidden and seemingly lost in them that could resurface only when these animals are taken back to their original wild environment. However, a healthy simulation feeding method for the captive cats would not only enhance their survival but also help in captivity adaptation. Interestingly, the behavior of lying while in captive feeding was dominant over standing, $87 \%$ and $13 \%$ respectively (fig. 7 ). The animal body system loses more energy while standing than lying. In lions, feeding on a prey is also supported by the forelimb-claws, thus, the position of lying on feeding would otherwise ease the cat's body physiology.

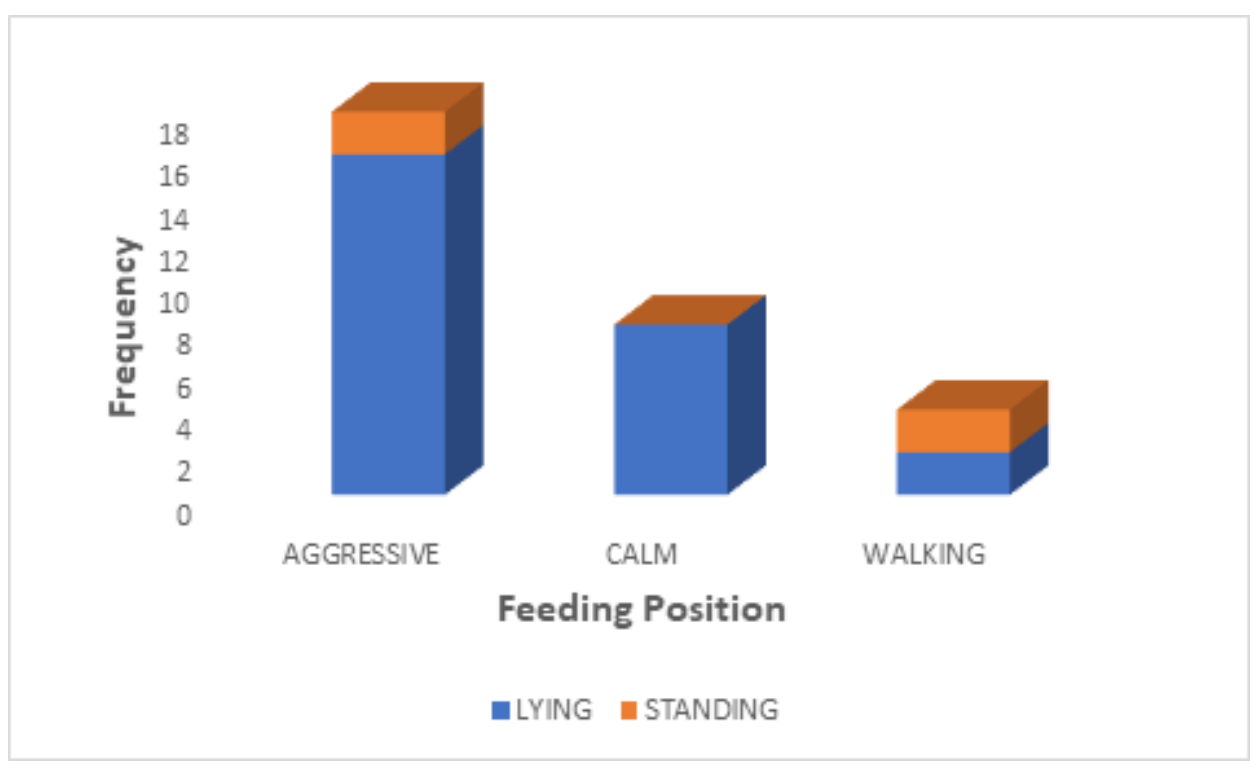

Fig6. Feeding behavior and feeding position 


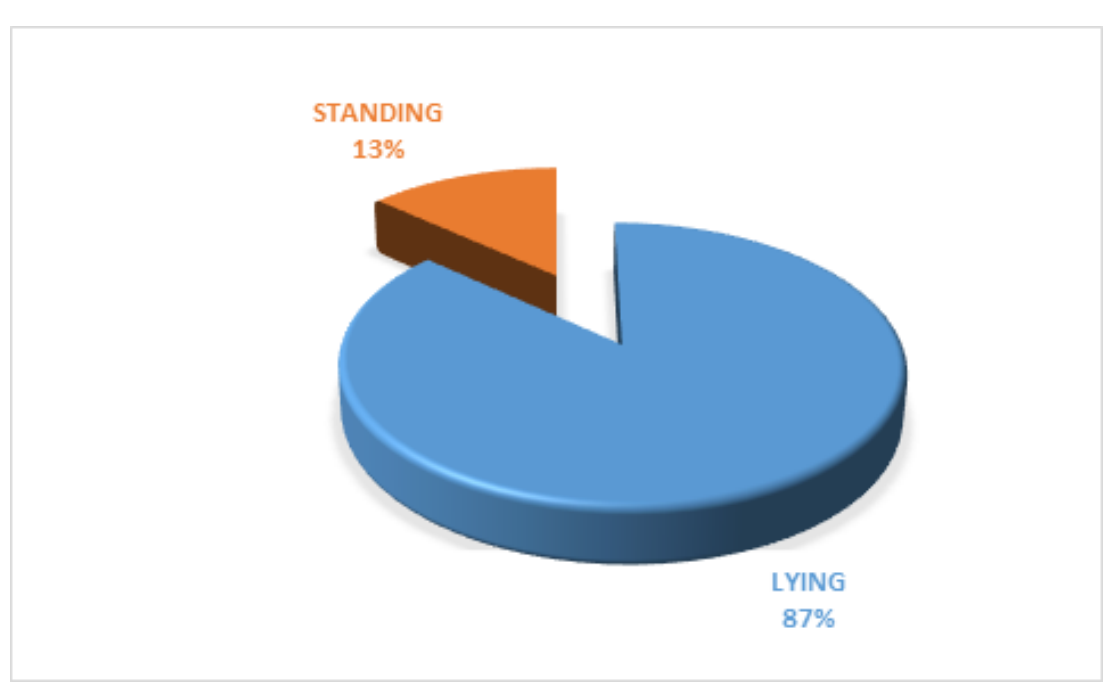

Fig7. Feeding position

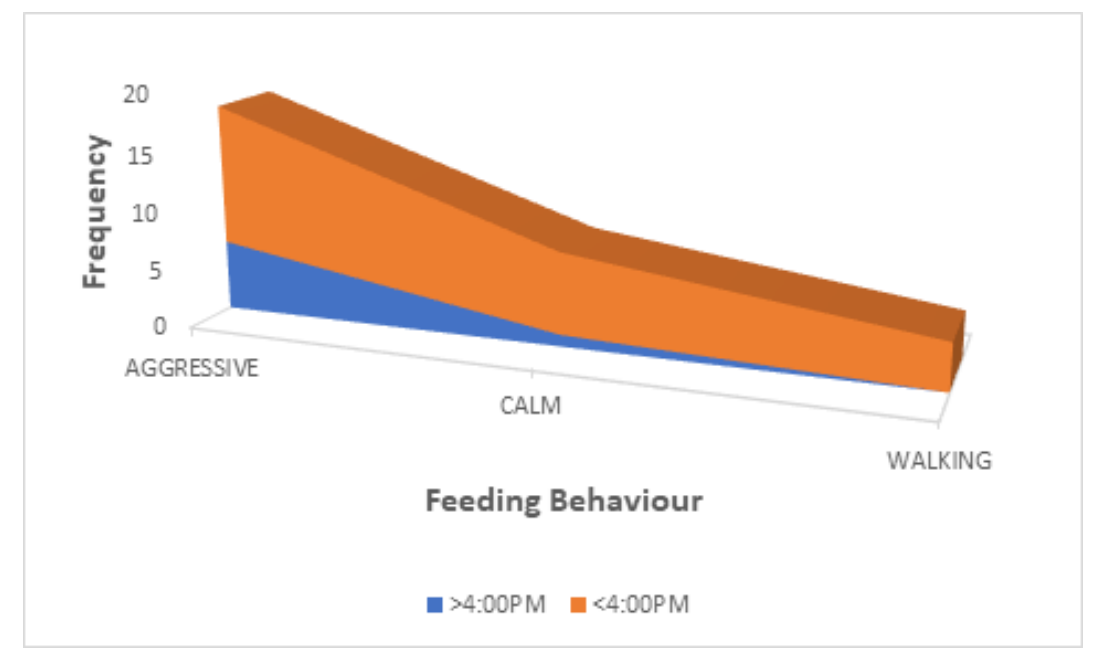

Fig8. Feeding time and feeding behavior

This study considered only three feeding related behaviors for the captive female lion, aggression, calm, and movement. Aggressive behavior was the most observed feeding behavior and recorded $60 \%$, while walking was the least, $13 \%$ (fig. 9). The favorable financial cost on cow meat as compared to chicken was a determinant factor in the animal feeding. Thought the difference in cost price of the two feeding components was not much, the management preferred cow meat that has more energy value. The preferred feeding time for the female lion was some minutes before 4:00pm and the animal was very much adapted to this time, however, in rare occasions the animal was fed above 4:00pm.

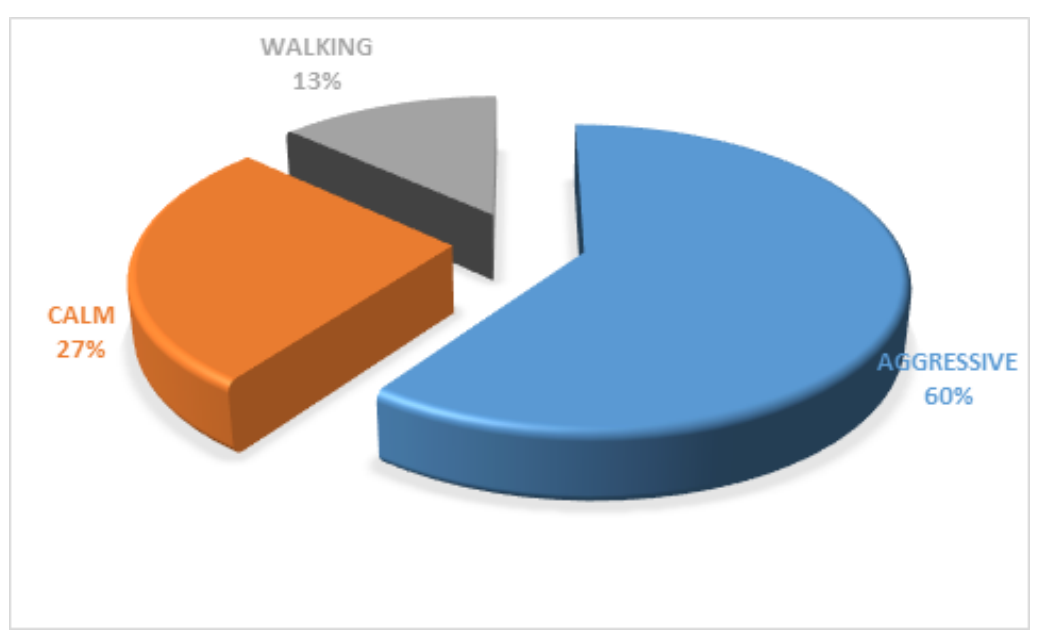

Fig9. Feeding behavior 
A significant link was recorded between the hygiene conditions of non-feeding environment on the position and behavior of the animal, $\mathrm{X}^{2}=18.592 \mathrm{df}=2, \mathrm{P}=0.000$ (fig.10) and $\mathrm{X}^{2}=4.617 \mathrm{df}=6, \mathrm{P}<0.05$ (fig.12) respectively. The animal displayed a spectrum of behaviors during the non-feeding periods, and the behaviors were resting, moving, roaring, and auto-grooming, recording an observation of $66 \%, 15 \%$, $10 \%$, and $9 \%$ respectively (fig. 11). Strangely, aggression was not observed during the absence of food in the enclosure, rather roaring, known to be used in the wild by lions in defending their territory, and inviting other pride members when a prey is caught was more significant. Nonetheless, in captivity a lion-roar may also symbolize hunger, the reason it was never heard during the feeding periods. The female lion was most observed in the outer enclosure during the non-feeding periods, and was more active in a dry environment. In the wild, the felid activities are affected by a wet weather environment, the reason the outer enclosure recorded more movement activity during a sunny weather.

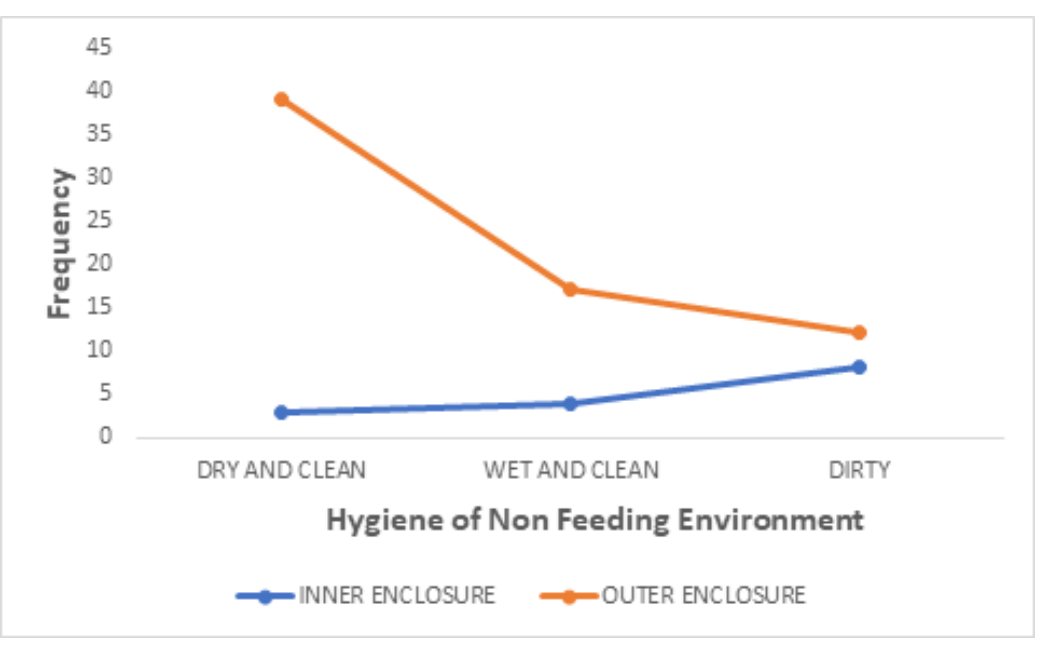

Fig10. Animal position and hygiene condition of non-feeding environment

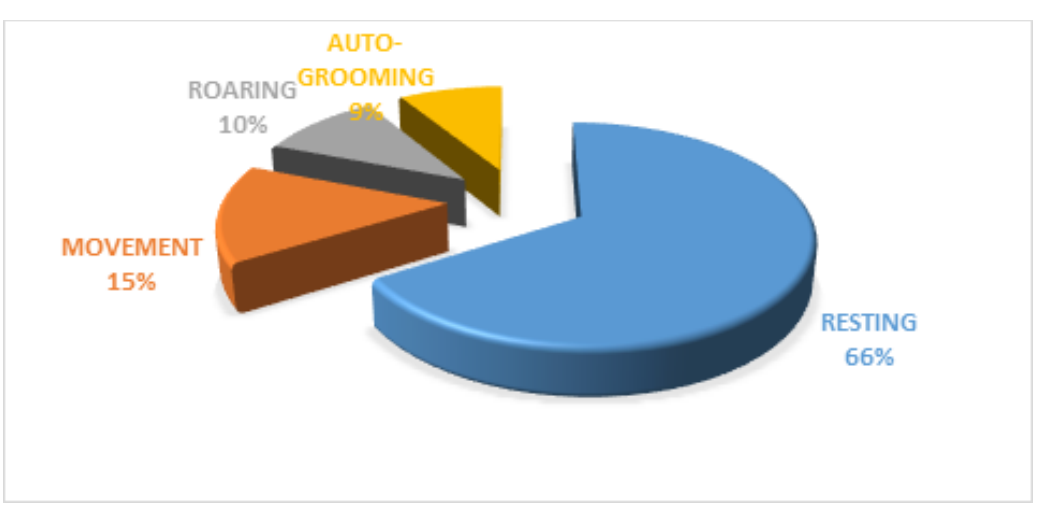

Fig11. Non feeding behavior

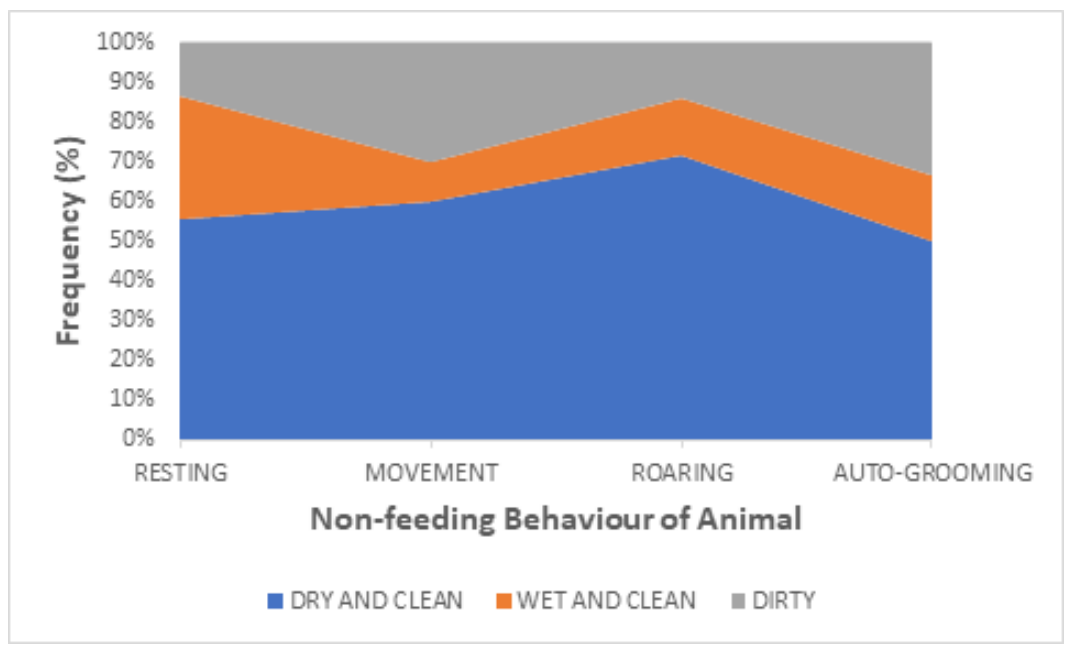

Fig12. Feeding behavior and hygiene condition of non-feeding environment 


\section{DISCUSSION}

Lions are opportunistic carnivores that have a strong innate drive to hunt, stalk, chase and kill their prey in the wild, both as individuals and as a group (Estes, 1991). Their active predatory instinct requires the need for food-based enrichment as well as for object enrichment to simulate a kill. Lions also have a well-defined sense of smell that is used in the wild for gathering information about their territory (Schaller, 1972). Sensory enrichment can stimulate lions to investigate their zoo territories in a similar manner. Enrichment should also address the social complexity of lions, and lion enclosures need to be as multifaceted as possible to mimic a natural environment. They should offer the lions opportunities to choose how and where they will spend their time.

Food is an inherently enriching item for the lion. Lions spend a quarter to a third of their daily activity hunting prey and consuming their kill (Sunquist \& Sunquist, 2002). Consequently, feeding a lion its food ration once daily, which can usually be consumed within minutes, may limit the enrichment properties it should have. There are ways to make food and feeding more enriching. For example, a variable feeding schedule could be implemented. There are studies to suggest that animals can benefit from an unreliable feeding schedule if it is paired with a reliable cue (Bassett \& Buchanan-Smith, 2007). One study of lions in a managed setting examined the effects of switching the cats from a conventional daily feeding schedule to a gorge and fast diet. Large meals were fed on a random schedule that resulted in increased digestibility and better weight maintenance (Altman, et al., 2005). Another strategy for making food more enriching is to hide, scatter or present it in a manner that requires the lions to "hunt" for their food. Offering a variety of food types may prove physically and mentally enriching.

Bones and carcasses give the animals a more naturalistic way to exhibit feeding behaviors, which may reduce stereotypic behavior as well as improve dental health (Bond \& Lindburg, 1990). A variety of bones are available from commercial zoo food distributors. Rabbits are a good carcass choice because they are available throughout the year from rabbit breeders. Deer carcasses can be obtained during deer hunting season from a meat processor. It is beneficial to the processor to have the unprocessed parts of the deer disposed of by the zoo and it is equally beneficial to the zoo to have the deer cleaned and prepared for consumption. The typical unclaimed portions of the deer that are readily available are rib cages with rib meat, heads, legs and hides, all of which receive great response from the lions while only slightly increasing dietary consumption.

The diet of wild lions is whole carcass. In zoos, whole carcass may or may not have the hide and viscera removed. Carcass typically refers to larger animals such as goats, sheep, calves, and deer. Ex-situ supplementation of whole carcasses can promote a wide range of feeding and foraging behaviors. Institutions choosing to feed carcass should be aware potential hazards that may exist including presence of pharmaceutical drugs, pesticides, toxic organic compounds, pathogenic bacteria (Harrison et al., 2006). The origin and history of the carcass should be known and institutions must follow USDA policy no. 25 (USDA, 1998) specifying feeding the carcass as soon as possible or processing into smaller pieces and freezing, avoiding sick animals, removing lead shot from animals euthanized by gunshot, avoiding animals with signs of central nervous system disease or at risk of transmissible spongiform encephalopathy, including animals with scrapie, chronic wasting disease, and those with John's disease. Whole carcass fed to lions includes deer, goats, sheep, whole or quartered, turkeys and chickens. Muscle contains too little calcium, vitamins A, $\mathrm{D}$, and $\mathrm{E}$ and other micronutrients to support health without additional sources of these nutrients. Muscle meat can be fed in combination with other diet items that meet the target nutrient levels so that additional supplementation is not required. For example, muscle meat is often utilized as a training tool or a medication vector. If muscle meat must be fed at a significant level in the diet or exclusively, the following supplementation is recommended per $2 \mathrm{~kg}$ of muscle (Ullrey \& Bernard, 1989):

Lions are the only truly social species of cat and they should be housed with conspecifics in exhibits that offer socially enriching opportunities. Interactions with enclosure mates are a continuous source of stimulation for social groups that is unavailable to singly-housed animals (Hosey et al., 2009). Facilities should be designed to offer enrichment opportunities for multiple lions, instead of individual lions, to encourage social behavior while taking care to prevent aggression. Lions are known to feed together in the wild, but when offering food enrichment, enough should be offered in the beginning so that all lions can have access to it in order to determine if the lions will fight over the food. Similarly, object enrichment should first be offered so that all lions in a particular enclosure can participate. This may mean having more than one prey-resistance device or having multiple elevated pallets for sleeping. If the lions are particularly 
social, they may be willing to "share" and less may need to be offered. Lions have exhibit wide range of behaviors and enrichment goals should be based on encouraging or discouraging these behaviors. They exhibit typical cat behaviors such as predatory and territorial behaviors but in addition, they also have social behaviors that are unique to lions.

Offering a variety of enclosure furniture such as different perches, substrates, scratching material or water sources can give enclosures and exhibits an element of complexity and give animals control in a habitat that offers limited variation. It also has the added benefit of allowing keepers to determine animal preferences. This knowledge can be used advantageously in such ways as encouraging animals to spend more time in public viewing areas; redirecting scratching behaviors from exhibit plantings; and possibly reducing stereotypic behavior. It has been suggested that adding appropriate complexity to an animal's environment can result in appropriate species-specific behavioral patterns (Maple \& Perkins, 1996). One final consideration when designing an enrichment program for lions: lions sleep approximately 20 hours per day in the wild and are active mostly between dusk and dawn (Nowak \& Paradiso, 1999). Enrichment aimed at increasing lion activity during the day may not be achieving the goal of promoting species appropriate behavior. It may be more beneficial for the lions to focus enrichment opportunities during the evening hours.

Staff members should be trained in all areas of animal behavior management. A reference library appropriate to the size and complexity of the institution should be available to all staff and volunteers to provide them with accurate information on the behavioral needs of the animals with which they work. Staff should be provided training on the principles of animal enrichment and training. Depending on the institution, this training may be provided by internal staff, consultants, or by sending staff to appropriate training courses. Before providing enrichment or training lions, staff should be familiar with the natural history and behavior of lions, the background of their individual lions, the husbandry routine for the area, the institutions training and enrichment program, and the principles of animal enrichment and training.

\section{CONCLUSION}

For many years, African lions were not a priority for conservation but in the last 2 decades, they have come under threat from a variety of factors, including habitat loss, human conflict, and disease from domestic animals. Retaliatory killing in east Africa and distemper and bovine tuberculosis outbreaks in southern Africa threaten the last large populations of lions on the planet.

However, the ex-situ management of lions in captivity in Sub Saharan Africa is intended for their population growth, preservation and protection. In Mvog-Betsi Zoo, the presence of the adult female lion has influenced the influx of tourists who have not been opportune to watch the activities of this big cat in the wild environment. Unfortunately, its zoo-presence is associated with a comparatively high financial and management cost. The feeding of the lioness with a natural feeding regime that includes a whole animal carcass of goat, sheet etc to enhance its feeding enrichment has not been achieved. On the other hand, zoo workers lack wildlife training on the management of lions in captivity, a situation considered to be aggravated by lack of a wildlife veterinary medical team in handling the health of this iconic wildlife species. The zoo management needs proper in-service training on wildlife behaviors, wildlife feeding regime and enrichment in captivity, wildlife ecology, zoonotic diseases of wildlife, and hospitality towards the tourists.

\section{REFERENCES}

[1] Altman, J. D., Gross, K. L., \& Lowry, S. R. (2005). Nutritional \& behavioral effects of gorge \& fast feeding in captive lions. Journal of Applied Animal Welfare Science, 8, 47-57.

[2] Altmann J (1974). Observational study of behavior: sampling methods. Behavior 48:227-265.

[3] Barry, K. A., Wojcicki, B. J., Middelbos, I. S., Vester, B. M., Swanson, K. S., \& Fahey, G. C. (2010). Dietary cellulose, fructooligosaccharides and pectin modify fecal protein catabolites and microbial populations in adult cats. Journal of Animal Science, 88, 2978-2987

[4] Bassett, L., \& Buchanan-Smith H. (2007). Effects of Predictability on the Welfare of Captive Animals. Applied Animal Behavior Science, 102, 223-245.

[5] Bond, J., \& Lindburg, D. (1990). Carcass Feeding of Captive Cheetahs (Acinonyx jubatus): The Effects of a Naturalistic Feeding Program on Oral Health and Psychological Well-being. Applied Animal Behavior Science, 26, 373-382.

[6] Clarke, B. C., \& Berry, H. H. (1992). Water flux in free-living lions (Panthera leo) in the Etosha National Park, Namibia. Journal of Mammalogy, 73(3), 552-558.

[7] Eloff, F. C. (1984). Food ecology of the Kalahari lion (Panthera leo vernayi). Koedoe, Supplement, 249-258. 
An Examination of the Nutritional Care and Feeding Behavior of an Adult Female Lion (Panthera leo) in Mvog-Betsi Zoo in Yaounde, Centre Region, Cameroon

[8] Edmonds, R. B. (2015). The Multilingual Zoo: Animals, Languages, and Symbolic Capital in Yaounde, Cameroon. Published M.A, thesis, University of California, Los Angeles

[9] Edwards, M. S., Gaffney, M., \& Bray, R. E. (2001). Influence of fiber source on apparent digestibility, rate of passage and fecal consistency in small felids fed a beef-based carnivore diet, 71-80.

[10]Estes, R. (1991). The Behavior Guide to African Mammals. Berkley: University of California Press.

[11] Haas, S. K., Hayssen, V., \& Krausman, P. R. (2005). Lion Panthera Leo. Mammalian Species, 762, 1-11

[12] Harrison, T. M., Harrison, S. H., Rumbeiha, W. K., Sikarskie, J. G., \& McClean, M. (2006). Surveillance for selected bacterial and toxicologic contaminants in donated carcass meat fed to carnivores. Journal of Zoo and Wildlife Medicine, 37, 102-107

[13] Hayward, M. W., \& Kerley, G. I. H. (2005). Prey preferences of the lion (Panthera leo). Journal of Zoology, 267, 309-322.

[14] Hosey, G., Melfi, V., \& Pankhurst, S. (2009). Zoo Animals: Behavior, Management and Welfare. Oxford University Press, Oxford.

[15] Maple, T., \& Perkins, L. (1996). Enclosure Furnishing and Structural Environmental Enrichment. D.

[16]Kleiman, M. Allen, K. Thompson \& S. Lumpkin (Eds.). Wild Mammals in Captivity: Principles and Techniques, 88-99.

[17] Martin P, Bateson P (2007). Measuring behavior: An introductory guide ( $3^{\text {rd }}$ Edition). Cambridge: Cambridge University Press.

[18] Melle E. M, Nkwatoh A. F \& Tim K. L (2017). The influence of some ecological factors on drill monkeys Mandrillus leucophaeus (Cuvier) - in Limbe wildlife center (LWC), Southwest Region, Cameroon. International Journal of Biodiversity and Conservation, Vol. 9(7), pp. 256-264,

[19] Nowak, R., \& Paradiso, J. (1999). Walker's Mammals of the World (6th ed.). Johns Hopkins University Press

[20] Rapson, J. A., \& Bernard, R. T. F. (2007). Interpreting the diet of lions (Panthera leo); a comparison of various methods of analysis. South African Journal of Wildlife Research, 37, 179-187.

[21] Sambrook, T., \& Buchanan-Smith, H. (1997). Control and Complexity in Novel Object Enrichment. Animal Welfare, 6, 207-216.

[22] Schaller, G. (1972). The Serengeti Lion: A Study in Predator-Prey Relations. Chicago: University of Chicago Press.

[23] Smuts, G. L. (1979). Diet of lions and spotted hyaenas assessed from stomach contents. South African Journal of Wildlife Research, 9, 19-25.

[24] Sunquist, M., \& Sunquist, F. (2002). Wild Cats of the World. Chicago: University of Chicago Press

[25]Ullrey, D. E., \& Bernard, J. B. (1989). Meat diets for performing exotic cats. Journal of Zoo and Wildlife Medicine, 20, 20-25

[26] USDA (1998). Animal Care Resource Guide: Nutrition for large felids.

[27] Van Valkenburgh, B. (1996). Feeding behavior in free-ranging, large African carnivores. Journal of Mammology, 77, 240-254

[28] Vester, B. M., Burke, S. L., Liu, K. J., Dikeman, C. L., Simmons, L. G., \& Swanson, K. S. (2010). Influence of feeding raw or extruded feline diets on nutrient digestibility and nitrogen metabolism of African wildcats (Felis lybica). Zoo Biology, 29, 676-686.

[29] Visser, H. (2009). Factors influencing lion (Panthera leo) home range, movement and diet in Waza National Park, Cameroon.

[30] Watts, J. C. (2011). Potential of alternative protein sources for exotic carnivores: observations and discussion. Paper presented at the 9th Conference of the AZA Nutrition Advisory Group on Zoo and Wildlife Nutrition, Kansas City, MO.

[31] Wynne, J. E. (1989). Comparative digestibility values in four species of felidae. Journal of Zoo and Wildlife Medicine, 20, 53-56.

Citation: Melle Ekane Maurice, et.al (2020). "The Ecological Significance on Primate Activity in KimbiFungom National Park, Northwest Region, Cameroon ". International Journal of Research Studies in Zoology (IJRSZ), vol. 6, no. 2, pp. 15-24, 2020. Available: DOI: http://dx.doi.org/10.20431/2454-941X.060202

Copyright: (C) 2020 Authors. This is an open-access article distributed under the terms of the Creative Commons Attribution License, which permits unrestricted use, distribution, and reproduction in any medium, provided the original author and source are credited. 